\title{
IDENTIFIKASI JUMLAH PRODUKSI PRODUK DENGAN METODE FUZZY TSUKAMOTO BERBASIS WEB
}

\author{
Dasril Aldo \\ Program Studi Sistem Informasi, STMIK GICI \\ email: dasrilaldo1994@gmail.com
}

\begin{abstract}
Abstrak
Logika fuzzy merupakan salah satu ilmu yang dapat menganalisa ketidakpastian. Salah satu metode aturan fuzzy adalah Tsukamoto, yaitu metode yang sering digunakan untuk membanguan sebuah sistem yang penalarannya menyerupai instuisi atau perasaan manusia. Proses perhitungannya cukup kompleks sehingga membutuhkan waktu relatif lama, tetapi metode ini memberikan hasil dengan nilai ketelitian yang tinggi. Hot Pangsit Nyonyor merupakan suatu perusahaan yang melakukan produksi pangsit dalam jumlah cukup besar setiap minggunya. Oleh karena itu, perencanaan jumlah produksi pangsit Hot Pangsit Nyonyor sangatlah penting. Agar dapat memenuhi permintaan pasar dengan tepat dan dengan jumlah yang sesuai. Dengan adanya masalah tersebut maka untuk menentukan jumlah produksi dalam memenuhi permintaan konsumen diperlukan suatu alternatif pemecahan masalah tanpa menambah fasilitas yang ada, yaitu dengan mengaplikasikan logika fuzzy Tsukamoto. Penerapan logika fuzzy Tsukamoto dalam perencanaan jumlah produksi Hot Pangsit Nyonyor, diharapkan perusahaan dapat mengatasi lonjakan permintaan konsumen.
\end{abstract}

Kata Kunci :Metode Fuzzy Tsukamoto, Web, Permintaan, Persediaan, Produksi

sisa per hari sebagai parameter dalam melakukan proses produksi. Penulis

\section{PENDAHULUAN}

Seiring dengan pengembangan teknologi dimasa sekarang, penggunaan teknologi informasi dapat dijadikan suatu media yang dapat membantu pekerjaan manusia. Seperti halnya teknologi informasi dibidang web yang dapat digunakan oleh siapa saja dengan mudah. Dengan kemudahan pengaksesan dan interface yang menarik akan menimbulkan kesenangan yang berbeda dibanding cara tradisional yang membutuhkan kertas untuk mengolah data. Kondisi tersebut merupakan kesempatan untuk memanfaatkan teknologi informasi web dalam implementasi pengolahan data logika Fuzzy Logic sehingga lebih efisien.

Alasan penulis mengangkat jumlah produksi hot pangsit dan jumlah produk

JURSIMA https://ejournal.stmikgici.ac.id/ Jurnal Sistem Informasi dan Manajemen menggunakan Logika Fuzzy Tsukamoto karena dalam masalah yang dibahas terdapat ketidak pastian atas jumlah produksi sedangkan metode Fuzzy itu sendiri merupakan satu metode untuk melakukan analisis sistem yang mengandung ketidakpastian.

Masalah yang ditangani pada penelitian ini adalah agar Hot Pangsit Nyonyor dapat menyeimbangkan persedian dan permintaan produksi.Namun Hot Pangsit Nyonyor masih belum mampu untuk menghasilkan hasil produksinya sesuai dengan permintaan.

Perancangan sistem informasi manajemen produksi, dilakukan dengan membangun aplikasi berbasis web. Penulis menggunakan logika Fuzzy Tsukamoto karena dalam masalah yang akan dibahas 
Volume 7 No. 1

Mei 2019

terdapat ketidakpastian atas jumlah produksi ini yang sangat cocok untuk menyelesaikan masalah yang dimaksud. Adapun tema atau judul yang akan dibahas adalah "Penerapan Metode Fuzzy Tsukamoto Untuk Penentuan Jumlah Produksi Hot Pangsit Nyonyor Di Kota Padang Berbasis Web".

\section{LANDASAN TEORI}

\section{Kecerdasan Buatan}

Kecerdasan buatan berasal dari bahasa Inggris "Artificial Intelligence" atau disingkat AI, yaitu intelligence adalah kata sifat yang berarti cerdas, sedangkan artificial artinya buatan. Kecerdasan buatan yang di maksud disini merujuk pada mesin yang mampu berpikir, menimbang tindakan yang diambil, dan mampu mengambil keputusan seperti yang dilakukan oleh manusia (Sutujo, dkk : 2011).

\section{Fuzzy Logic}

Konsep tentang logika fuzzy diperkenalkan oleh Prof. Lotfi Astor Zadeh pada tahun 1962. Logika fuzzy adalah metodologi sistem control pemecahan masalah, yang cocok untuk diimplementasikan pada sistem, mulai dari sistem yang sederhana, sistem kecil, embedded system, jaringan PC, multichannel atau workstation berbasis akuisisi data, dan system control. Metodologi ini dapat diterapkan pada perangkat keras, perangkat lunak, atau kombinasi keduanya (Sutojo, dkk, 2010).

Menurut Rizki, Novia Sestri (2016), " logika fuzzy adalah suatu cara untuk memetakan suatu ruang input

JURSIMA https://ejournal.stmikgici.ac.id/ Jurnal Sistem Informasi dan Manajemen kedalam suatu ruang output". Dengan logika fuzzy sesuatu yang dapat memiliki nilai diantara range 0 dan 1. "Fuzzy" berarti kabur atau samar. Logika fuzzy adalah logika multivalued yang memungkinkan untuk mendefinisikan nilai menengah diantara dua logika/evaluasi konvensional yang berbeda, seperti benar/salah, iya/tidak, tinggi/rendah, panas/dingin, dan lain-lain. Oleh karena itu logika ini disebut logika samar. Sehingga dalam teori fuzzy sesuatu dapat bernilai salah atau benar secara bersamaan.

Sebelum munculnya teori logika fuzzy logic dikenal sebuah logika tegas (crisp logic) yang memiliki nilai benar dan salah secara tegas. Sebaliknya Logika fuzzy adalah suatu logika yang memiliki nilai kekaburan atau kesamaran (fuzzyness) antara benar dan salah. Dalam teori logika fuzzy suatu nilai bisa bernilai benar dan salah secara bersamaan. Namun berapa besar kebenaran dan kesalahan suatu nilai tergantung pada bobot keanggotaan yang dimilikinya. Orang yang belum mengenal logika fuzzy akan mengira bahwa logika fuzzy adalah suatu yang amat rumit dan tidak menyenangkan. Namun, sekali orang mengenalnya, akan sangat tertarik dan akan menjadi pendatang baru untuk ikut serta mempelajari logika fuzzy. Logika fuzzy dikatakan sebagai logika baru yang lama, sebab ilmu tentang logika fuzzy modern dan metode baru ditemukan beberapa tahun yang lalu, padahal sebenarnya konsep tentang logika fuzzy itu sendiri sudah ada pada diri kita sejak lama(Mustika, Alva Fanisya \& Sutrisno, 2016). 


\section{Dasar-dasar Fuzzy Logic}

Untuk lebih memahami logika fuzzy, perhatikan tentang konsep himpunan fuzzy. Himpunan fuzzy memiliki 2 atribut, yaitu (Sutojo, dkk, 2010) :

1. Linguistik, yaitu nama suatu kelompok yang mewakili suatu keadaan tertentu dengan menggunakan bahasa alami, misalnya DINGIN, SEJUK, PANAS, mewakili variabel temperatur.

2. Numeris, yaitu suatu nilai yang menunjukkan ukuran dari suatu variabel, misalnya 10,35, 40 dan sebagainya. Disamping itu, ada beberapa hal yang harus dipahami dalam memahami logika fuzzy.

3. Variabel fuzzy, yaitu variabel yang akan dibahas dalam suatu sistem fuzzy.

4. Himpunan fuzzy, yaitu suatu kelompok yang mewakili suatu keadaan tertentu dalam suatu variabel fuzzy.

5. Semesta pembicaraan, yaitu seluruh nilai yang diizinkan untuk dioperasikan dalam suatu variabel fuzzy.

\section{Fungsi Keanggotaan Fuzzy Logic}

Fungsi keanggotaan adalah suatu grafik yang mewakili besar dari derajat keanggotaan masing-masing variabel input yang berada dalam interval antara 0 dan 1 . satu cara yang dapat digunakan untuk mendapatkan nilai keanggotaan adalah dengan melalui pendekatan fungsi. Apabila U menyatakan himpunan universal dan $\mathrm{A}$ adalah himpunan fungsi

JURSIMA https://ejournal.stmikgici.ac.id/ Jurnal Sistem Informasi dan Manajemen fuzzy dalam $\mathrm{U}$, maka A dapat dinyatakan

sebagai pasangan terurut. Ada beberapa fungsi yang bisa digunakan (Irzal Arief Wisky, 2016).

\section{Metode Tsukamoto}

Pada metode Tsukamoto, setiap konsekuen pada aturan yang berbentuk IFThen harus direpresentasikan dengan suatu himpunan fuzzy dengan fungsi keanggotaan yang menonton sebagai hasilnya, output hasil inferensi dari tiaptiap aturan diberikan secara tegas (crisp) berdasarkan $\alpha$-predikat (fire strength). Hasil akhirnya di peroleh dengan menggunakan rata-rata terbobot (Maryaningsih, dkk, 2013).

Secara umum, model fuzzy Tsukamoto adalah (Sutojo, dkk, 2010) :

If ( $\mathrm{X}$ is $\mathrm{A})$ and $(\mathrm{Y}$ is $\mathrm{B})$ Then $(\mathrm{Z}$ is $\mathrm{C})$

Dimana A, B, dan C adalah himpunan fuzzy. Dalam inferensinya, metode Tsukamoto menggunakan tahapan berikut:

1. Fuzzyfikasi

Pembentukan basis pengetahuan Fuzzy (Rule dalam bentuk IF...THEN).

2. Mesin Inferensi

Menggunakan fungsi implikasi MIN untuk mendapat nilai $\alpha-$ predikat tiap-tiap rule $(\alpha 1, \alpha 2$, $\alpha 3, \ldots \ldots . . \alpha n)$.

Kemudian masing-masing nilai $\alpha$-predikat ini digunakan untuk menghitung keluaran hasil inferensi secara tegas (crisp) masingmasing rule (z1, z2, z3,.....zn)

3. De fuzzyfikasi 
Volume 7 No. 1

Mei 2019

$$
\begin{aligned}
& \text { Menggunakan metode Rata- } \\
& \text { Rata (Average) }
\end{aligned}
$$

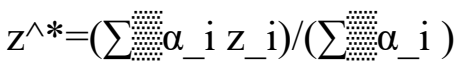
(2018), dalam peneltiannya tentang penentuan jumlah produksi nanas menggunakan metode Tsukamoto dapat disimpulkan bahwa akurasi sistem pendukung keputusan berdasarkan 49 data yang diuji memiliki nilai kesalahan sebesar 0,000607, jika dalam nilai persen dapat dituliskan dengan angka 0,0607 \%, hal tersebut menunjukkan bahwa sistem pendukung keputusan penentuan jumlah produksi nanas menggunakan metode fuzzy Tsukamoto.

\section{Usaha Kecil Menengah (UKM)}

Usaha kecil dan menengah (UKM) adalah pelaku bisnis yang bergerak pada berbagai bidang usaha, yang menyentuh kepentingan masyarakat. Peran UKM sangat penting dalam pembangunan perekonomian di Indonesia, terutama dalam penyediaan tenaga kerja dan sumber penghasilan bagi kelompok masyarakat yang berpenghasilan rendah. UKM juga membantu Pemerintah dalam upaya pemberantasan kemiskinan melalui pengembangan perekonomian sistem kerakyatan. Melihat peran dan potensinya, pengembangan UKM ini sangat penting guna meningkatkan kesejahteraan masyarakat sekaligus mendukung peningkatan perekonomian daerah (Sukesti Fatmasari \& Nurhayati, 2015)..

\section{Produksi}

Menurut penelitian William, dkk (2015) menyatakan produksi secara umum

JURSIMA https://ejournal.stmikgici.ac.id/ Jurnal Sistem Informasi dan Manajemen dapat di artikan sebagai pengarahan dan pengendalian berbagai kegiatan yang mengolah berbagai jenis sumber daya untuk membuat barang atau jasa tertentu.

Sistem produksi tidak hanya terdapat pada industri manufaktur, tetapi juga dalam industri jasa dan perbankan, asuransi, pasar swalayan, dan rumah sakit. Sistem produksi dan operasi dalam industri jasa menggunakan bauran yang berbeda dari masukan yang dipergunakan dalam industri manufaktur. Sistem produksi yang sering di pergunakan dapat dibedaan atas 3 macam yaitu (William, dkk, 2015):

Proses produksi yang kontiniu (continuous process) dimana peralatan produksi yang di gunakan disusun dan diatur dengan memperhatikan urutan kegiatan atau routing dalam menghasilkan produk tersebut, serta arus bahan dalam proses telah terstandarisasi.

Proses produksi terputus (intermitten process) - dimana kegiatan produksi dilakukan tidak standart, tetapi didasarkan pada produk yang di kerjakan, sehingga peralatan produksi yang digunakan di susun dan di atu yang dapat bersifat lebih luwes (flexible) untuk dapat dipergunakan bagi menghasilkan produk dan berbagai ukuran.

Proses produksi yang bersifat proyek dimana kegiatan produksi dilakukan pada tempat dan waktu yang berbeda-beda, sehingga peralatan produksi yang digunakan di tempatkan di tempat atau lokasi proyek tersebut dilaksanakan dan pada saat yang direncanakan. Setiap sistem suatu organisasi, sistem pengorganisasian terdiri dari beberapa subsistem,yang merupakan susistem fungsional. 
Volume 7 No. 1

Mei 2019

\section{METODE PENELITIAN}

Kerangka penelitian adalah urutan yang akan dilakukan dalam suatu penelitian. Agar langkah-langkah yang diambil penulis dalam perancangan ini tidak melenceng dari pokok pembicaraan dan lebih mudah dipahami, maka urutan langkah-langkah penelitian akan dibuat secara sistematis sehingga dapat dijadikan pedoman yang jelas dan mudah untuk menyelesaikan permasalahan yang ada. Urutan langkah-langkah yang akan dibuat pada penelitian ini dapat dilihat pada gambar berikut ini :

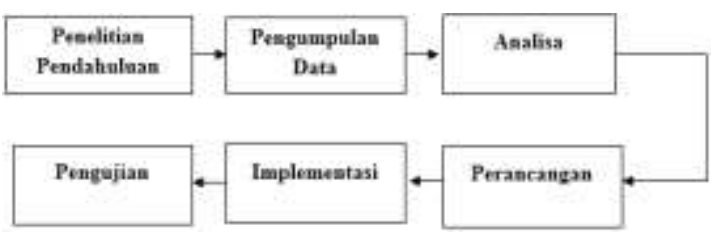

Gambar 1. Metodologi Penelitian

\section{HASIL DAN PEMBAHASAN}

\section{Analisa}

\section{Analisa Data}

Proses analisa data yaitu merupakan salah satu tahapan yang penting dalam penelitian ini, karena pada tahap inilah nantinya dilakukan dentifikasi terhadap masalah yang ada pada Hot Pangsit Di Kota Padang, serta melakukan penganalisaan terhadap data yang diperoleh, dimana data dijadikan bahan untuk pembuatan aplikasi ini, data yang diperoleh adalah data permintaan dan data persediaan yang ada pada Hot Pangsit Di Kota Padang.

Analisa masalah dilakukan agar penemuan-penemuan masalah yang didapat dapat diketahui penyebabnya, sehingga dari analisa masalah tersebut didapatkan suatu bentuk pemecahan masalah. Pada penelitian ini, dari kesimpulan analisa data yang didapatkan

JURSIMA https://ejournal.stmikgici.ac.id/ Jurnal Sistem Informasi dan Manajemen dari pihak Hot Pangsit Di Kota Padang dapat dianalisa masalahnya, yakni didapatkan bahwa dalam mengolah produksi langsung mendapatkan permintaan dari konsumen untuk kemudian diproses dan diolah berdasarkan berapa banyak jumlah permintaan konsumen dan juga dalam penentuan jumlah prosuksi masih dengan cara manual sehingga sering terjadi kelebihan ataupun tidak sesuai dengan jumlah permintaan konsumen yang dapat menyebabkan kerugian pada perusahaan sehingga cara ini dianggap masih kurang efektif.

Pemecahan masalah adalah suatu cara yang dapat menyelesaikan masalah yang telah dijelaskan pada analisa masalah di atas tersebut adalah dengan membangun Fuzzy inference system untuk prediksi produksi Hot Pangsit menggunakan metode Tsukamoto yang dapat menghasilkan prediksi untuk menentukan berapa jumlah produksi Hot Pangsit di Hot Pangsit Di Kota Padang. Berikut adalah tabel produksi pada Hot Pangsit Di Kota Padang:

\section{Tabel 1. Tabel Produksi}

\begin{tabular}{|c|c|c|c|}
\hline Tanggal & $\begin{array}{c}\text { Permin } \\
\text { taan }\end{array}$ & $\begin{array}{c}\text { Perse } \\
\text { dian }\end{array}$ & $\begin{array}{c}\text { Prod } \\
\text { uksi }\end{array}$ \\
\hline 01 Oktober 2018 & 660 & 115 & 583 \\
\hline 03 Oktober 2018 & 837 & 125 & 750 \\
\hline 04 Oktober 2018 & 844 & 137 & 745 \\
\hline 05 Oktober 2018 & 1073 & 111 & 1000 \\
\hline 06 Oktober 2018 & 776 & 64 & 750 \\
\hline 07 Oktober 2018 & 700 & 138 & 600 \\
\hline 08 Oktober 2018 & 687 & 125 & 600 \\
\hline 10 Oktober 2018 & 968 & 206 & 800 \\
\hline 11 Oktober 2018 & 754 & 92 & 700 \\
\hline 12 Oktober 2018 & 799 & 137 & 700 \\
\hline 13 Oktober 2018 & 908 & 196 & 750 \\
\hline 14 Oktober 2018 & 876 & 114 & 800 \\
\hline 15 Oktober 2018 & 904 & 142 & 800 \\
\hline
\end{tabular}


Volume 7 No. 1

Mei 2019

\begin{tabular}{|c|c|c|c|}
\hline 17 Oktober 2018 & 794 & 89 & 820 \\
\hline 18 Oktober 2018 & 905 & 143 & 800 \\
\hline 2018 & 1049 & 142 & 945 \\
\hline 20 Oktober 2018 & 1064 & 137 & 965 \\
\hline 21 Oktober 2018 & 1054 & 117 & 975 \\
\hline 22 Oktober 2018 & 1046 & 84 & 1000 \\
\hline 24 Oktober 2018 & 1163 & 176 & 1025 \\
\hline 25 Oktober 2018 & 1087 & 125 & 1000 \\
\hline 26 Okto & 887 & 125 & 800 \\
\hline 27 Oktober 2018 & 912 & 125 & 825 \\
\hline 28 Oktober 2018 & 1087 & 125 & 1000 \\
\hline 29 Oktober 2018 & 1087 & 125 & 1000 \\
\hline 30 Oktc & 1062 & 125 & 975 \\
\hline 01 November 2018 & 670 & 161 & 583 \\
\hline 03 November 2018 & 902 & 100 & 815 \\
\hline 04 November 2018 & 832 & 98 & 745 \\
\hline 05 November 2018 & 1087 & 117 & 1000 \\
\hline 06 November 2018 & 837 & 131 & 750 \\
\hline 07 Nove & 887 & 98 & 800 \\
\hline 08 Nove & 887 & 90 & 800 \\
\hline 10 Noven & 897 & 121 & 810 \\
\hline 11 November 2018 & 1087 & 160 & 1000 \\
\hline 12 November 2018 & 1087 & 118 & 1000 \\
\hline 13 November 2018 & 837 & 119 & 750 \\
\hline 14 November 2018 & 887 & 102 & 800 \\
\hline 15 November 2018 & 887 & 114 & 800 \\
\hline 17 November 2018 & 907 & 160 & 820 \\
\hline 18 November 2018 & 887 & 122 & 800 \\
\hline eer 2018 & 1032 & 151 & 945 \\
\hline 20 November 2018 & 1052 & 113 & 965 \\
\hline 21 November 2018 & 1062 & 133 & 975 \\
\hline 22 November 2018 & 1087 & 120 & 1000 \\
\hline 24 November 2018 & 1097 & 120 & 1010 \\
\hline 25 November 2018 & 1087 & 161 & 1000 \\
\hline 26 November 2018 & 887 & 110 & 800 \\
\hline 27 November 2018 & 912 & 128 & 825 \\
\hline 28 November 2018 & 887 & 125 & 800 \\
\hline 29 November 2018 & 883 & 134 & 800 \\
\hline 30 November 2018 & 1062 & 197 & 975 \\
\hline
\end{tabular}

Sumber : Hot Pangsit Di Kota Padang

Analisa Proses

Adapun analisa terhadap sistem aplikasi Fuzzy yang dibangun menerapkan metode Fuzzy Tsukamoto, metode Tsukamoto merupakan satu metode yang digunakan untuk menghitung inputan Fuzzy dalam mengatasi kesulitan dari memprediksi suatu kejadiaan yang akan datang, dalam hal penelitian ini yaitu menerapkan Fuzzy Tsukamoto untuk memprediksi produksi Hot Pagsit.

Adapun analisa proses yang dilakukan sebagai berikut :

\section{Model Base Metode Tsukamoto}

Di dalam model base ini, secara umum terdapat tiga langkah untuk menentukan jumlah produksi berdasarkan data persediaan dan data permintaan dengan metode Tsukamoto, yaitu: mendefinisikan variabel, inferensi, dan defuzzifikasi (menentukan output crisp).

\section{Mendefinisikan Variabel Fuzzy}

Pada tahap ini, nilai keanggotaan himpunan permintaan dan persediaan saat ini dicari menggunakan fungsi keanggotaan himpunan Fuzzy dengan memperhatikan nilai maksimum dan nilai minimum data 1 periode terakhir dari tiap variabel. Variabel 1 periode terakhir antara lain: variabel permintaan, variabel persediaan dan variabel produksi.

\section{Proses Perhitungan Manual Fuzzy Tsukamoto}

Analisa ini dilakukan dengan menggunakan data produksi yang didapatkan dari pihak HOT PANGSIT DI KOTA PADANG. Pada metode Fuzzy Tuskamoto, baik baik variabel input

JURSIMA https://ejournal.stmikgici.ac.id/ Jurnal Sistem Informasi dan Manajemen 
Volume 7 No. 1

Mei 2019

maupun output dibagi menjadi satu atau lebih himpunan Fuzzy. Dalam penentuan jumlah produksi berdasarkan data persediaan dan permintaan, variabel input dibagi menjadi dua yaitu variabel persediaan dan permintaan. Serta satu variabel output yaitu produksi. Penentuan variabel yang digunakan dalam penelitian ini terlihat pada tabel berikut ini :

Tabel 2. Semesta pembicaraan

\begin{tabular}{|l|l|c|}
\hline Fungsi & Variabel & $\begin{array}{c}\text { Semesta } \\
\text { Pembicaraan }\end{array}$ \\
\hline \multirow{2}{*}{ Input } & Permintaan & $660-1163$ \\
\cline { 2 - 3 } & Persediaan & $64-206$ \\
\hline Output & Produksi & $583-1025$ \\
\hline
\end{tabular}

Dari variabel yang dimunculkan, kemudian disusun domain himpunan Fuzzy. Berdasarkan domain tersebut, selanjutnya ditentukan fungsi keanggotaan dari masing-masing variabel seperti terlihat pada tabel 4.3 berikut ini :

Tabel 3. Fungsi Keanggotaan

\begin{tabular}{|l|c|c|c|}
\hline $\begin{array}{l}\text { Fung } \\
\text { si }\end{array}$ & Variabel & $\begin{array}{c}\text { Himpun } \\
\text { an }\end{array}$ & $\begin{array}{c}\text { Semesta } \\
\text { Pembicara } \\
\text { an }\end{array}$ \\
\hline \multirow{2}{*}{ Input } & $\begin{array}{c}\text { Perminta } \\
\text { an }\end{array}$ & $\begin{array}{c}\text { Turun } \\
\text { Naik }\end{array}$ & $\begin{array}{c}660-911 \\
912-1163\end{array}$ \\
\cline { 2 - 4 } & $\begin{array}{c}\text { Persedia } \\
\text { an }\end{array}$ & $\begin{array}{c}\text { Sedikit } \\
\text { Banyak }\end{array}$ & $\begin{array}{c}64-135 \\
136-206\end{array}$ \\
\hline \multirow{2}{*}{$\begin{array}{c}\text { Outp } \\
\text { ut }\end{array}$} & $\begin{array}{c}\text { Produksi } \\
\text { Berkuran } \\
\text { g }\end{array}$ & $\begin{array}{c}\text { Bertamb } \\
\text { ah }\end{array}$ & $\begin{array}{c}583-804 \\
805-1025\end{array}$ \\
\hline
\end{tabular}

JURSIMA https://ejournal.stmikgici.ac.id/ Jurnal Sistem Informasi dan Manajemen
Dalam metode Tsukamoto terdapat 4 langkah dasar untuk melakukan proses logika Fuzzy, yaitu fuzzifikasi, pembentukan rule, mesin inferensi, dan defuzzifikasi. berikut penjabaran langkah metode Tsukamoto dengan data kedua yaitu tanggal 1 bulan Dese, ber 2018. Dimana input PERMINTAAN MIN yaitu 660 Pcs, PERMINTAAN MAX 1163 Pcs. PERSEDIAAN MIN 64 Pcs, dan PERSEDIAAN MAX 206 Pcs, serta output PRODUKSI MIN 583 Pcs, dan PRODUKSI MAX 1025 Pcs.

a. Data tanggal 1 April 2019 Input :

- Permintaan : 700 Pcs

- Persediaan : 110 Pcs

Output :

- Produksi :

1. Fuzzifikasi

Permintaan; terdiri atas 2 himpunan, yaitu NAIK dan TURUN

$\mu$ Turun[700] $=(1163-700) /(1163-660)$ $=0,920$

$\mu \mathrm{Naik}[700]=(700-660) /(1163-660)$ $=0,080$

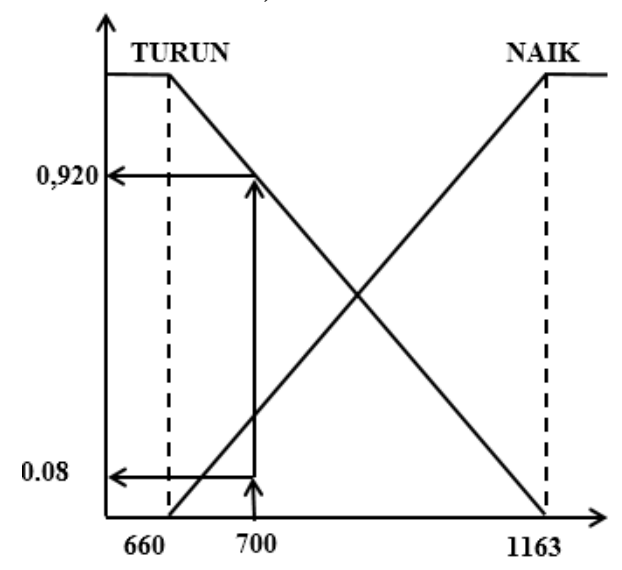

Gambar 2 Fungsi Permintaan

Persediaan; terdiri atas 2 himpunan, yaitu BANYAK dan SEDIKIT

$\mu$ Sedikit $[110]=(206-110) /(206-64)$

$$
=0,676
$$


Volume 7 No. 1

Mei 2019

$$
\begin{aligned}
\mu \text { Banyak }[110] & =(110-64) /(206-64) \\
& =0,324
\end{aligned}
$$

Untuk lebih jelas fungsi keanggotaan permintaan dapat dijelaskan pada gambar berikut:

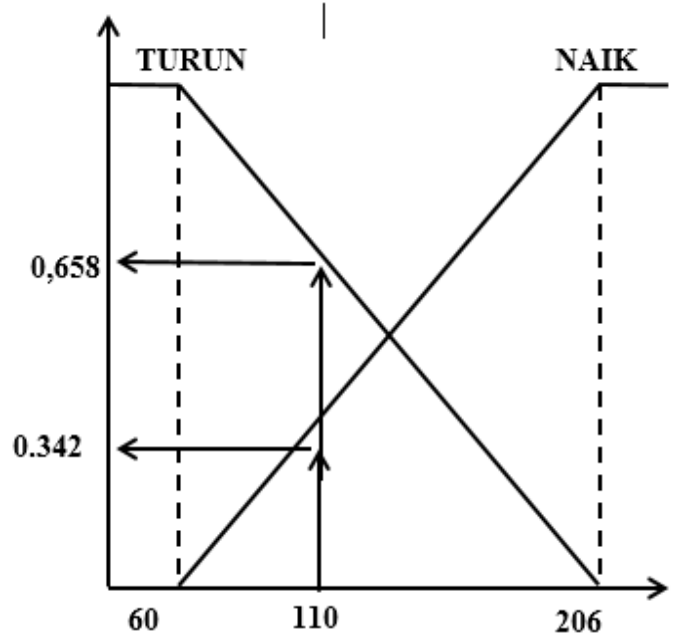

Gambar 3 Fungsi Persediaan

Produksi; terdiri atas 2 himpunan, yaitu BERTAMBAH dan BERKURANG

$\mu$ Bertambah $[\mathrm{z}]=(1025-\mathrm{z}) /(1025-$ 583);

$\mu$ Berkurang $[\mathrm{z}]=(\mathrm{z}-583) /(1025-583)$ berikut:

Sehingga terbentuk seperti gambar

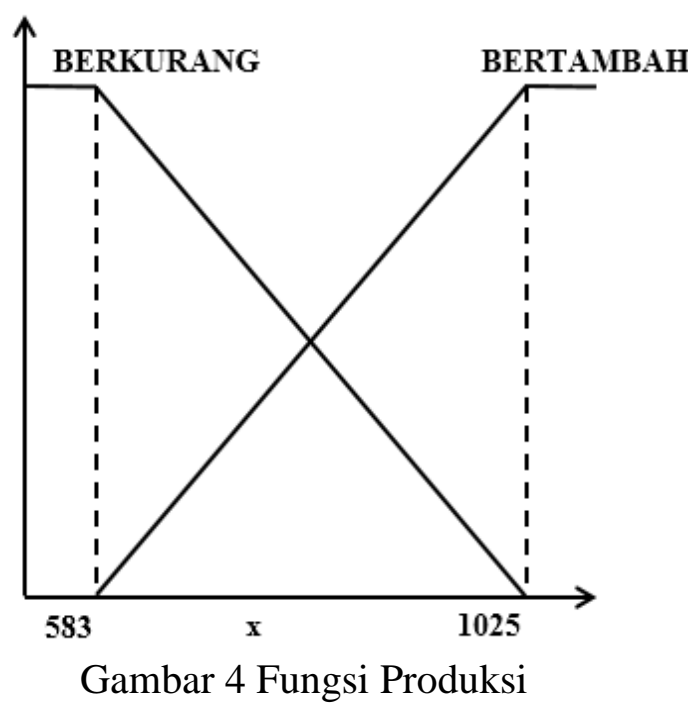

JURSIMA https://ejournal.stmikgici.ac.id/ Jurnal Sistem Informasi dan Manajemen
2. Pembentukan Rule

Berdasarkan

pembentukan himpunan dan variabel Fuzzy sebelumnya dimana terdapat variabel input terdiri dari permintaan dan persediaan serta vjariabel output terdiri dari produksi. Dan juga terdapat himpunan Fuzzy terbagi atas 2 variabel maka dapat dibentuk beberapa rule sebagai proses perhitungan yang akan digunakan Seperti berikut ini :

a. [R1] = IF Permintaan TURUN And Persediaan BANYAK THEN Produksi Hot Pangsit BERKURANG

b. $[R 2]=$ IF Permintaan TURUN And Persediaan SEDIKIT THEN Produksi Hot Pangsit BERKURANG

c. $[\mathrm{R} 3]=$ IF Permintaan NAIK And Persediaan BANYAK THEN Produksi Hot Pangsit BERTAMBAH

d. $[R 4]=$ IF Permintaan NAIK And Persediaan SEDIKIT THEN Produksi Hot Pangsit BERTAMBAH

3. Mesin Inferensi

a. $[\mathrm{R} 1]=\mathrm{IF}$ Permintaan TURUN And Persediaan BANYAK THEN Produksi Hot Pangsit BERKURANG $\alpha$-predikat ${ }_{1}=\mu$ Turun $\cap$ Banyak

$$
\begin{aligned}
& =\min (\mu \text { Turun }, \mu \text { Banyak }) \\
& =\min (0,920 ; 0,324) \\
& =0,324
\end{aligned}
$$

Menurut fungsi keanggotaan himpunan Produksi Hot Pangsit BERKURANG dalam aturan Fuzzy [R1] maka nilai $\mathrm{z} 1$ adalah:

$$
\begin{array}{lr}
(1025-\mathrm{z} 1) /(1025-583) & =0,324 \\
(1025-\mathrm{z} 1) /(442) & =0,324 \\
(1025-\mathrm{z} 1)=0,324 * 442= & 143,208
\end{array}
$$


Volume 7 No. 1

Mei 2019

$$
\begin{array}{ll}
\mathrm{Z}_{1} & =1025-143,206 \\
\mathrm{Z}_{1} & =881,792
\end{array}
$$

b. $[R 2]=$ IF Permintaan TURUN And Persediaan SEDIKIT THEN Produksi Hot Pangsit BERKURANG $\alpha$-predikat $2=\mu$ Turun $\cap$ Sedikit $=\min (\mu$ Turun, $\mu$ Sedikit $)$ $=\min (0,920 ; 0,676)$ $=0,676$

Menurut fungsi keanggotaan himpunan Produksi Hot Pangsit BERKURANG dalam aturan Fuzzy [R2] maka nilai $\mathrm{Z}_{2}$ adalah:

$$
\begin{aligned}
& (1025-\mathrm{z} 2) /(1025-583)=0,676 \\
& (1025-\mathrm{z} 2) /(442) \quad=0,676 \\
& (1025-\mathrm{z} 2)=0,676 * 442=298,792 \\
& \mathrm{Z}_{2} \quad=1025-298,792 \\
& \mathrm{Z}_{2} \quad=726,208
\end{aligned}
$$

c. $[R 3]=$ IF Permintaan NAIK And Persediaan BANYAK THEN Produksi Hot Pangsit BERTAMBAH $\alpha$-predikat $3=\mu$ Naik $\cap$ Banyak

$$
\begin{aligned}
& =\min (\mu \text { Naik, } \mu \text { Banyak }) \\
& =\min (0,080 ; 0,324) \\
& =0,080
\end{aligned}
$$

Menurut fungsi keanggotaan himpunan Produksi Hot Pangsit BERTAMBAH dalam aturan Fuzzy [R3] maka nilai $\mathrm{Z}_{3}$ adalah:

$$
\begin{array}{cl}
(\mathrm{z} 3-1025) /( & (1025-583)=0,080 \\
(\mathrm{z} 3-1025) /( & =0,080 \\
(\mathrm{z} 3-1025) & =0,080 * 442=35,36 \\
\mathrm{Z}_{3} & =35,36+1025 \\
\mathrm{Z}_{3} & =1060,36
\end{array}
$$

d. [R4] = IF Permintaan NAIK And Persediaan SEDIKIT THEN Produksi Hot Pangsit BERTAMBAH

$\alpha$-predikat ${ }_{4}=\mu$ Naik $\cap$ Sedikit

$$
\begin{aligned}
& =\min (\mu \text { Naik, } \mu \text { Sedikit }) \\
& =\min (0,080 ; 0,676) \\
& =0,080
\end{aligned}
$$

JURSIMA https://ejournal.stmikgici.ac.id/ Jurnal Sistem Informasi dan Manajemen
Menurut fungsi keanggotaan himpunan Produksi Hot Pangsit BERTAMBAH dalam aturan Fuzzy [R4] maka nilai $\mathrm{Z}_{2}$ adalah:

$$
\begin{aligned}
((\mathrm{z} 4-1025) /(1025-583) & =0,080 \\
(\mathrm{z} 4-1025) & =0,080 \\
(\mathrm{z} 4-1025) & =0,080 * 442=35,36 \\
\mathrm{Z}_{4} & =35,36+1025 \\
\mathrm{Z}_{4} & =1060,36
\end{aligned}
$$

4. DeFuzzyfikasi

Pada metode Tsukamoto, untuk menentukan output crisp digunakan defuzifikasi

rata-rata terpusat, yaitu:

$$
\begin{aligned}
& Z=\frac{\boldsymbol{\alpha} 1 * z 1+\alpha 2 * z 2+\alpha \mathbf{3} * z 3+\alpha \mathbf{4} * z \mathbf{4}}{\boldsymbol{\alpha} \mathbf{1}+\boldsymbol{\alpha} \mathbf{\alpha} \boldsymbol{\alpha}+\boldsymbol{\alpha} \mathbf{3}+\boldsymbol{\alpha} 4} \\
& Z=(0,324 * 881,792)+\left(0,676^{*}\right. \\
& 726,208)+(0,080 * 1060,36)+(0,080 * \\
& 1060,36) /(0,324+0,676+0,080+0,080) \\
& Z=946,274816 / 1,16 \\
& Z=815,75415172414
\end{aligned}
$$

Jadi, menurut perhitungan dengan metode Tsukamoto diatas, jumlah Hot Pangsit yang harus diproduksi Hot Pagsit sebanyak 815,75415172414 Pcs dan dibulatkan menjadi 816.

\section{HASIL}

Hasil dari penelitian ini berupa aplikasi Fuzzy yang dapat menghasilkan angka produksi untuk periode yang akan datang.

\section{KESIMPULAN}

Dari uraian masalah di atas, serta berdasarkan analisa dari bab-bab yang ada, maka dapat ditarik kesimpulan sebagai berikut:

1. Aplikasi ini terbukti mampu melakukan penelusuran terhadap jumlah produksi dan solusi 
berdasarkan penelusuran jawaban atas pertanyaan yang diberikan oleh sistem. Dengan menjalankan aplikasi ini telah membantu manager produksi dalam mengenali jumlah dan permintaan produksi per hari.

2. Aplikasi ini dapat memberikan informasi yang terbaru dan memudahkan manager produksi. sebagai contoh meningkatkan jumlah produksi hot pangsit dan jumlah produk sisa perhari sebagai parameter dalam melakukan proses produksi. Dimana penentuan tersebut dihasilkan dari proses perhitungan Fuzzy Tsukamoto.

3. Dengan mengaplikasikan logika Fuzzy Tsukamoto melalui coding menggunakan PHP dan penyimpanan data di database $M y S Q L$, sistem dapat di impelementasikan berbasis website yang bersifat Fuzzy Tsukamoto.

\section{KATA TRIMAKSIH}

Terimakasih kepada dosen pembimbing yang telah membantu dalam penyusunan jurnal ini, dan trima kasih kepada Agi Ramandha yang telah menyediakan data penelitian ini, dan tidak lupa saya trimakasih kepada Allah atas segala rahmat dan karunia yang telah di berikan kepada saya, dan trimakasih untuk semua yang mendukung penelitian ini.

\section{DAFTAR PUSTAKA}

Infotama, J. M., et al. "Metode Logika Fuzzy Tsukamoto dalam Sistem Pengambilan Keputusan Penerimaan Beasiswa." Jurnal Media Infotama 9.1 (2013): 140165.
Kusumadewi, Sri. "Artificial intelligence (teknik dan aplikasinya)." Yogyakarta: Graha Ilmu 278 (2003).

Mustika, Fanisya Alva, and Sutrisno Sutrisno. "Model Evaluasi Kinerja Karyawan Dengan Metode Fuzzy Sugeno Pada Resto Abtl." String (Satuan Tulisan Riset Dan Inovasi Teknologi) 1.1 (2016).

Prayogi, Agus.. "Sistem Pendukung Keputusan Untuk Penentuan Jumlah Produksi Nanas Menggunakan Metode Fuzzy Tsukamoto (Studi kasus PT.Great Giant Pineapple)" : Jurnal Pengembangan Teknologi Informasi dan Ilmu Komputer eISSN: 2548-964X Vol. 2, No. 6: Universitas Brawijaya (2018).

Rizki, Sestri Novia. "Analisa Tingkat Kepuasan Masyarakat Dengan Kualitas Kinerja Kepolisian Menggunakan Metode Fuzzy Logic Sugeno." Majalah Ilmiah Upi Yptk 23.1 (2016).

Rosa, A. S. "Shalahuddin." M.,-Rekayasa Perangkat Lunak Terstruktur dan Berorientasi Objek\|, 2nd Ed, Bandung: Informatika (2014).

Sukesti, Fatmasari, and Nurhayati Nurhayati. "Strategi Pengembangan UKM Melalui Peningkatan Modal Kerja dengan Variabel Intervening Pengembangan Bisnis Pada UKM Makanan Kecil di Kota Semarang." (2015).

William, William, et al. "Pengembangan Sistem Informasi Produksi pada Nikko Bakery." JSM (Jurnal SIFO Mikroskil) 16.2 (2015): 165-174. 
ISSN 2338-1523

E-ISSN 2541-576X

Volume 7 No. 1

Mei 2019

Wisky, Irzal Arief. "Logika Fuzzy Dalam

Sistem Pendukung Keputusan

Untuk Analisa Pendistribusian

Raskin (Studi Kasus Di

Kecamatan Bukit Sundi)."

Komputer Teknologi Informasi

3.2 (2016). 